\title{
The Relationship of Dietary Pattern and Genetic Risk Score with the Incidence of Dyslipidemia: 14-Year Follow-Up Cohort Study
}

\author{
Seon-Joo Park ${ }^{1,+}\left(\mathbb{D}\right.$, Myung-Sunny Kim ${ }^{2,3,+} \mathbb{D}$, Sang-Woon Choi ${ }^{4, *}$ and Hae-Jeung Lee ${ }^{1, *(\mathbb{D}}$ \\ 1 Department of Food and Nutrition, College of BioNano Technoloyg, Gachon University, \\ Gyeonggi 13120, Korea; chris0825@hanmail.net \\ 2 Research Group of Healthcare, Korea Food Research Institute, Wanju 55365, Korea; truka@kfri.re.kr \\ 3 Department of Food Biotechnology, Korea University of Science and Technology, Daejeon 34113, Korea \\ 4 Chaum Life Center, CHA University, Seoul 06062, Korea \\ * Correspondence: sang.choi@cha.ac.kr (S.-W.C.); skysea@gachon.ac.kr or skysea1010@gmail.com (H.-J.L.); \\ Tel.: +82-31-750-5968 (H.-J.L.); Fax: +82-31-724-4411 (H.-J.L.) \\ + These authors contributed equally to this work.
}

Received: 20 November 2020; Accepted: 13 December 2020; Published: 16 December 2020

\begin{abstract}
This study was conducted to investigate the relationship between dietary pattern and genetic risk score (GRS) for dyslipidemia risk among Korean adults. Hypercholesterolemia and hypertriglyceridemia defined as total cholesterol $\geq 240 \mathrm{mg} / \mathrm{dL}$ and triglyceride $\geq 200 \mathrm{mg} / \mathrm{dL}$ or use dyslipidemia medication. The GRS was calculated by summing the risk alleles of the selected seven single-nucleotide polymorphisms related to dyslipidemia. Dietary patterns were identified by principal component analysis based on the frequency of 36 food groups, "whole grain and soybean products" pattern, "meat, fish and vegetables" pattern, and "bread and noodle" pattern were identified. Hazard ratios (HRs) and 95\% confidence intervals (CIs) were estimated using the multivariate Cox proportional hazards regression model. High intake of a "whole grain and soybean products" pattern decreased risks of hypercholesterolemia (HR: 0.82, 95\% CI: 0.72-0.93, $p$ for trend $=0.0006$ ) and hypertriglyceridemia (HR: $0.85,95 \%$ CI: $0.75-0.97, p$ for trend $=0.0344$ ). In the highest tertile of GRS, the "whole grain and soybean products" pattern was inversely related to hypercholesterolemia risk. Therefore, for people with genotypes that can cause hypercholesterolemia, eating whole grains and soybean products may have a meaningful response, these results could be utilized for genome-based nutrition management.
\end{abstract}

Keywords: diet; dyslipidemia; genetics; cohort study

\section{Introduction}

Dyslipidemia has been closely linked to the development of coronary artery disease (CAD) and is a modifiable risk factor using dietary therapy [1]. According to a 2015 report from the Korean Society of Lipidology and Atherosclerosis, $47.8 \%$ of Korean adults over 30 years were diagnosed with dyslipidemia [2]. Several contributing factors including low physical activity, smoking, and unhealthy diet have been linked to dyslipidemia and subsequently cardiovascular diseases (CVD) worldwide [3]. Recently, dietary pattern approach is widely used in nutrition epidemiology research rather than the conventional emphasis on individual foods, nutrients or dietary components analysis [4]. Dietary patterns are thought to be associated with CVD and dyslipidemia. Vegetarian dietary patterns have beneficial effects on CVD [5], and adherence to healthy eating patterns have been associated with a lower risk of developing CVD in three large prospective cohort studies [6]. Additionally, 
several cross-sectional studies conducted to investigate an association between dietary patterns and dyslipidemia [7-9].

The lipid metabolism could be affected by specific genetic variation [10], common single-nucleotide polymorphisms (SNPs) modulate the individual response to the diet which could explain how gene-diet interactions affect lipid metabolism [11]. The effect of any single SNP on the risk of coronary heart disease (CHD) is however, too small, so the definition of genetic risk score (GRS) has arisen based on the combined impact of multiple SNPs leading to CHD [12]. The GRS is a simple and intuitive approach aggregating disease-related loci for predicting disease susceptibility [13]. It has been reported that GRS is associated with incident CVD in the Framingham Heart Study [14] and dyslipidemia among Brazilian [15]. Furthermore, the GRS modified the association between diet quality and dyslipidemia among Swedish cohort [16]. We hypothesized that the GRS of selected genetic variants would be related the risk of dyslipidemia and interact with dietary patterns. To the best of our knowledge, there is only a few studies have been performed to examine the association between dietary pattern and dyslipidemia in middle-aged Korean adults $[17,18]$. However, there was no finding that identified the interaction of genetic variation and dietary patterns on dyslipidemia in middle-aged Koreans.

In this study, we conducted to investigate the association between dietary pattern and GRS with the incidence of dyslipidemia in Korean adults using 14-years follow-up cohort data.

\section{Materials and Methods}

\subsection{Subjects}

The epidemiology data of the Ansung-Ansan cohort were obtained from the Korean Genome and Epidemiology Study (KoGES) conducted by the Korea Disease Control and Prevention Agency. The Ansung-Ansan cohort is an ongoing, prospective cohort study on Korean adults (40-69 years at baseline, $n=10,030$ ) that began in 2001-2002. The follow-up examinations are conducted biennially. The cohort study design has been described in detail previously [19]. Informed consent was obtained from all study participants. The study protocol was approved by the Gachon University Institutional Review Board (1044396-201903-HR-041-03).

\subsection{Methods}

\subsubsection{Nutritional Assessment and Dietary Pattern Analysis}

Dietary intake was assessed using validated 103-food items, semi-quantitative food frequency questionnaire (SQFFQ) [20]. The frequency of servings was classified into nine categories (never or seldom, 1 time/month, 2-3 times/month, 1-2 times/week, 3-4 times/week, 5-6 times/week, 1 time/day, 2 times/day, and 3 times or more/day). The size of the food item was classified into small, medium, and large. Among 10,030 participants, 9704 subjects had completed SQFFQ (96.8\%). The nutrients intake of 103 food items was determined by the weight derived from the consumption frequency and portion size of each food items. The average nutrients intake of participants was calculated as the sum of the nutrient intake from each food item. The nutrient compositions used data from the seventh edition food composition tables of the Korean Nutrition Society [21].

To decrease the complexity, 103 food items were categorized into 36 groups, based on the food and nutrient composition similarity. Dietary patterns were derived using factor analysis based on the frequency of 36 food groups. The factors were rotated by an orthogonal transformation using the varimax rotation function to obtain a simpler structure and greater interpretability. To determine the number of factors, we considered eigenvalues $>2$ and inspection of scree plots. We decided to retain three major dietary factors.

All subjects had a dietary pattern score of three dietary patterns by weighing their intake of each food contributing to that pattern. Participants were divided into quartiles according to dietary pattern score of three dietary patterns. 


\subsubsection{Definition of Dyslipidemia}

The criteria for dyslipidemia followed the Clinical Practice Guideline of Korean Society of Lipid and Atherosclerosis [22]. Hypertriglyceridemia defined as elevated triglyceride (TG) level greater than $200 \mathrm{mg} / \mathrm{dL}$ and hypercholesterolemia defined as total cholesterol greater than $240 \mathrm{mg} / \mathrm{dL}$ or currently use any anti-dyslipidemic drug for controlling blood lipid level. Among participants who were not diagnosed or recognized with hypertriglyceridemia, participants with a fasting TG level $>200 \mathrm{mg} / \mathrm{dL}$ in the health examination were considered to have hypertriglyceridemia [23]. Among 10,030 participants, we excluded subjects as follows: subjects without dietary data $(n=326)$, subjects without blood TG or total cholesterol information $(n=3)$, subject taking hypolipidemic medication ( $n=57)$, subjects diagnosed dyslipidemia at baseline examination $(n=2214$ for hypertriglyceridemia, $n=904$ for hypercholesterolemia), and subjects didn't attend the follow-up examination ( $n=694$ for hypertriglyceridemia, $n=840$ for hypercholesterolemia). For the risk analysis of hypertriglyceridemia and hypercholesterolemia, a total of 6736 subjects and 7900 subjects were included, respectively.

\subsubsection{Measurement of Covariates}

Height and weight were measured to the nearest $0.1 \mathrm{~cm}$ and $0.1 \mathrm{~kg}$, respectively, by trained staff using a scale and a wall-mounted extensometer. Body mass index (BMI) was calculated as the weight in kilograms $(\mathrm{kg}) /$ height in meters $(\mathrm{m})$ squared.

The general characteristics and lifestyle data were collected by an interviewer-administered questionnaire. We considered age, residual area (Ansung (rural) or Ansan (urban)), income (monthly household income; $<1,500,000$ won, and $\geq 15,000,000$ won), education level (elementary school graduation or less, middle school graduation, high school graduation, and college graduation or higher), smoking status (current smoker or non-smoker), alcohol drinking status (current drinker or non/ex-drinker), regular exercise (yes or no), BMI, and total energy intake as potential confounding factors.

\subsubsection{Genotyping and GRS}

The genotyping of KoGES participants has been described in detail previously [19,24]. In brief, genotyping of SNPs was conducted using the Affymatrix Genome-wide Human SNP array 5.0, and to improve the coverage, SNP imputation was performed using IMPUTE (v246) containing the 1000 Genomes Phase I as a reference panel. Finally, 5,908,513 SNPs of 8840 participants were used in this analysis. Among them, 7 independent SNPs reported in a recent genome-wide association study (GWAS) of dyslipidemia [25-27] were selected for GRS. These SNPs that had a minor allele frequency in Asian $>0.15$ and have been robustly associated with dyslipidemia $\left(p<5 \times 10^{-7}\right)$. The selected seven SNPs were rs10889353 (ANGPTL3), rs7557067 (APOB), rs780092 (GCKR), rs1919127 (C2orf16), rs2954029 (TRIB1), rs174547 (FADS1-FADS2-FADS3), and rs2266788 (APOA5). We hypothesized an additive genetic model for each SNP applying a linear weight of 0,1 , or 2 to genotypes containing 0 , 1 , or 2 risk alleles, respectively, and the counted GRS of the seven selected SNPs was generated by summing the number of risk alleles for each SNP [28].

\subsubsection{Statistical Analysis}

Descriptive statistics such as means values and standard deviation (SD) were used to summarize continuous variables and frequencies were expressed as percentages. The difference between groups was tested using the $t$-test for continuous variables and chi-square test for categorical variables. Multivariable-adjusted Cox proportional hazards regression model was conducted to compare the hazard ratios (HRs) and 95\% confidence intervals (CIs) for dyslipidemia incidence risk according to the dietary pattern scores. Cox proportional hazards regression models were adjusted for age, sex, residual area, education level, household income, smoking status, alcohol drinking status, regular exercise, BMI, and total energy intake. To examine gene-diet interactions, we stratified subjects into 
tertile categories according to GRS and stratified participants into quartile categories according to "whole grain and soybean products" dietary pattern score. Then we performed stratified analyses to compare the relationship between dietary patterns and the HRs of dyslipidemia according to the GRS categories adjusted the same confounding factors as previous analysis. To test for trends, the factor scores entered into the model as continuous terms. A significant difference was defined as $p<0.05$. All statistical analyses were performed using SAS 9.4 (SAS Institute Inc., Cary, NC, USA).

\section{Results}

\subsection{Dietary Pattern Analysis}

Three dietary patterns were identified from the factor analysis. Factor loadings and variances of each dietary pattern are shown in Table 1. Positive loading indicates that the dietary variable is positively associated with the factor and negative loading indicates an inverse association of the factor. The "meat, fish and vegetables" pattern featured a high consumption of green-yellow vegetables, root vegetables, meats, and fishes. The "bread and noodle" pattern had high positive factor loading for bread, noodles, and rice cake. The "whole grain and soybean products" pattern was characterized by high consumption of rice with grains (whole grain) and soybeans and soybean products whereas it had a negative loading for white rice and instant ramen.

Table 1. Factor loading * matrix for 3 dietary patterns from the food frequency questionnaire.

\begin{tabular}{|c|c|c|c|}
\hline Food Groups & Meat, Fish and Vegetables & Bread and Noodle & $\begin{array}{l}\text { Whole Grain and } \\
\text { Soybean Products }\end{array}$ \\
\hline White rice & & & -0.83 \\
\hline Rice with grains & & & 0.85 \\
\hline Ramen & & 0.40 & -0.21 \\
\hline Noodles & & 0.39 & \\
\hline Other noodles & & 0.61 & \\
\hline Dumplings & & 0.61 & \\
\hline Rice cake & & 0.57 & \\
\hline Bread & & 0.66 & \\
\hline Pizza/Hamburger & & 0.37 & \\
\hline Flake & & 0.32 & \\
\hline Cakes & & 0.36 & \\
\hline Snacks/Sweets & & 0.24 & \\
\hline Butter/Margarine & & 0.31 & \\
\hline Potatoes & 0.31 & 0.45 & \\
\hline Soybeans and beans products & 0.24 & & 0.36 \\
\hline Nuts & 0.15 & 0.24 & \\
\hline Kimchi & 0.25 & & \\
\hline Green-yellow vegetables & 0.61 & & \\
\hline Root vegetables & 0.62 & & \\
\hline Pickle/Salt-fermented fish & 0.37 & & \\
\hline Mushrooms & 0.52 & & \\
\hline Fruits & 0.48 & & \\
\hline Meats & 0.64 & & \\
\hline Eggs & 0.37 & & \\
\hline White fish & 0.62 & & \\
\hline external blue colored fish & 0.59 & & \\
\hline Anchovy & 0.39 & & 0.24 \\
\hline Cuttlefish/Octopus & 0.52 & & \\
\hline Fish cake & 0.39 & & \\
\hline Shellfish & 0.55 & & \\
\hline Seaweeds & 0.44 & & 0.21 \\
\hline Milk & & & 0.23 \\
\hline Dairy products & 0.21 & & 0.24 \\
\hline
\end{tabular}


Table 1. Cont.

\begin{tabular}{cccc}
\hline Food Groups & Meat, Fish and Vegetables & Bread and Noodle & $\begin{array}{c}\text { Whole Grain and } \\
\text { Soybean Products }\end{array}$ \\
\hline Carbonated drinks & & & \\
Coffee & 0.23 & & \\
Green tea and other drinks & 4.21 & 2.87 & 2.03 \\
Variance explained & & \\
\hline
\end{tabular}

* factor loading coefficient greater than 0.2 are shown for simplicity.

\subsection{Characteristics of Subjects by Each Dietary Pattern}

Table 2 shows the general characteristics of participants by factor score quartiles for each dietary pattern. A highest factor score group for the "meat, fish and vegetables" pattern was younger, had higher BMI, higher energy intake, more male and more likely to live in an urban area, more educated, had higher income, and more regular exercise. Subjects with the higher score for the "Bread and noodle" pattern were younger, higher energy intake, higher total cholesterol and low TG. The highest quartile group of "whole grain and soybean products" pattern was older, had higher BMI and energy intake, higher total cholesterol and low TG, less educated, less likely to be a current smoker and drinker, and more likely to have regular exercise.

Table 2. Baseline characteristics of the study participants across quartile (Q) of dietary pattern scores.

\begin{tabular}{|c|c|c|c|c|c|c|}
\hline & \multicolumn{2}{|c|}{ Meat, Fish and Vegetables } & \multicolumn{2}{|c|}{ Bread and Noodle } & \multicolumn{2}{|c|}{ Whole Grain and Soybean Products } \\
\hline & Q1 $(n=2426)$ & $\mathrm{Q} 4(n=2426)$ & Q1 $(n=2426)$ & Q4 $(n=2426)$ & Q1 $(n=2426)$ & Q4 (n= 2426) \\
\hline Mean \pm SD & Q1 & Q4 & Q1 & Q4 & Q1 & Q4 \\
\hline Age & $54.9 \pm 0.2$ & $50.7 \pm 0.2 * * *$ & $55.2 \pm 0.2$ & $49.7 \pm 0.2 * * *$ & $51.3 \pm 0.2$ & $53.7 \pm 0.2 * * *$ \\
\hline BMI & $24.4 \pm 0.1$ & $24.8 \pm 0.1^{* * *}$ & $24.6 \pm 0.1$ & $24.6 \pm 0.1$ & $24.4 \pm 0.1$ & $24.7 \pm 0.1^{* * *}$ \\
\hline Energy & $1585.4 \pm 11.5$ & $2472.9 \pm 17.4^{* * *}$ & $1720.8 \pm 13.4$ & $\underset{* * *}{2412.4 \pm 16.6}$ & $1918.4 \pm 15.0$ & $2050.3 \pm 13.6^{* * *}$ \\
\hline Total cholesterol & $190.7 \pm 0.7$ & $192.0 \pm 0.7$ & $190.0 \pm 0.7$ & $192.7 \pm 0.7 *$ & $191.1 \pm 0.7$ & $193.5 \pm 0.8^{* *}$ \\
\hline HDL cholesterol & $44.6 \pm 0.2$ & $44.7 \pm 0.2$ & $44.2 \pm 0.2$ & $45.1 \pm 0.2^{* *}$ & $44.6 \pm 0.2$ & $45.1 \pm 0.2$ \\
\hline Triglyceride & $162.5 \pm 2.1$ & $162.7 \pm 2.2$ & $165.1 \pm 2.0$ & $163.4 \pm 2.3$ & $167.2 \pm 2.2$ & $158.1 \pm 2.2 *$ \\
\hline Male (\%) & 43.2 & $49.5^{* * *}$ & 40.5 & $51.4^{* * *}$ & 62.9 & $34.0 * * *$ \\
\hline \multicolumn{7}{|l|}{ Area (\%) } \\
\hline Rural & 64.5 & $45.3^{* * *}$ & 62.2 & $39.9^{* * *}$ & 58.8 & $40.0^{* * *}$ \\
\hline Urban & 35.5 & 54.7 & 37.8 & 60.1 & 41.2 & 60.0 \\
\hline \multicolumn{7}{|l|}{ Education (\%) } \\
\hline Elementary school & 48.7 & $25.3^{* * *}$ & 49.3 & $21.3^{* * *}$ & 32.9 & $35.2 * * *$ \\
\hline Middle school & 21.3 & 23.2 & 22.9 & 20.8 & 24.0 & 21.6 \\
\hline High school & 22.2 & 34.7 & 20.9 & 37.7 & 30.5 & 29.2 \\
\hline $\begin{array}{l}\text { College or higher } \\
\text { degree }\end{array}$ & 7.8 & 16.8 & 6.9 & 20.3 & 12.6 & 14.0 \\
\hline \multicolumn{7}{|l|}{ Income (\%) } \\
\hline$<1,500,000$ won & 66.5 & $41.7^{* * *}$ & 64.7 & $40.1^{* * *}$ & 54.0 & $49.4^{* * *}$ \\
\hline$\geq 1,500,000$ won & 33.5 & 58.3 & 35.3 & 59.9 & 46.0 & 50.6 \\
\hline \multicolumn{7}{|l|}{ Current drinking (\%) } \\
\hline $\begin{array}{c}\text { Yes } \\
\text { Current smoking (\%) }\end{array}$ & 40.9 & $51.0 * * *$ & 41.9 & $51.5^{* * *}$ & 56.1 & $38.5^{* * *}$ \\
\hline $\begin{array}{c}\text { Yes } \\
\text { Regular exercise (\%) }\end{array}$ & 17.2 & 18.8 & 14.8 & $20.2 * * *$ & 21.1 & $16.1^{* * *}$ \\
\hline Yes & 21.0 & $33.9^{* * *}$ & 22.3 & $33.2 * * *$ & 21.2 & $35.2 * * *$ \\
\hline
\end{tabular}

SD: standard deviation, HDL: high-density lipoprotein; BMI: body mass index. ${ }^{*} p<0.05,{ }^{* *}$ at $p<0.01$ and ${ }^{* * *}$ at $p<0.001$.

\subsection{Analysis of Dyslipidemia Risk by Dietary Pattern}

During the 14-year follow-up period, 2128 subjects (average follow up period, 8.50 years) and 2123 subjects (average follow up period, 8.34 years) were newly diagnosed with hypercholesterolemia and hypertriglyceridemia, respectively. Table 3 shows the analysis of dyslipidemia risk by dietary pattern score. After dividing the subjects into quartiles for each dietary pattern, the group with the highest factor score of "whole grain and soybean products" dietary pattern (rich in whole grain, soybeans, tofu, soybean paste, etc.) had a significantly lower risk of hypercholesterolemia (HR: $0.82,95 \%$ CI: $0.72-0.93, p$ for trend $=0.0006$ ) and hypertriglyceridemia 
(HR: $0.85,95 \%$ CI: $0.75-0.97, p$ for trend $=0.0344$ ) than the group with the lowest factor score after multi-adjusted confounding variables.

Table 3. Hazard ratios (HR) and 95\% confidence interval (CI) for the risk of incident dyslipidemia according to dietary pattern score.

\begin{tabular}{|c|c|c|c|c|c|c|c|}
\hline & & \multirow{2}{*}{ No of Total } & \multirow{2}{*}{ No of Cases } & \multicolumn{2}{|c|}{ Model 1} & \multicolumn{2}{|c|}{ Model 2} \\
\hline & & & & \multicolumn{2}{|c|}{ HR 95\% CI } & \multicolumn{2}{|c|}{ HR 95\% CI } \\
\hline \multicolumn{8}{|c|}{ Hypercholesterolemia } \\
\hline \multirow{4}{*}{$\begin{array}{c}\text { Meat, fish and } \\
\text { vegetables }\end{array}$} & Q1 & 1967 & 530 & 1.00 & & 1.00 & \\
\hline & Q2 & 1973 & 533 & 1.02 & $0.90-1.15$ & 0.92 & $0.81-1.04$ \\
\hline & Q3 & 1977 & 548 & 1.06 & $0.94-1.19$ & 0.95 & $0.83-1.08$ \\
\hline & $\widetilde{Q} 4$ & 1983 & 517 & 1.02 & $0.90-1.15$ & 0.91 & 0.79-1.05 \\
\hline \multirow[t]{2}{*}{$p$ for trend } & & & & 0.7574 & & 0.3079 & \\
\hline & Q1 & 1992 & 520 & 1.00 & & 1.00 & \\
\hline \multirow{3}{*}{$\begin{array}{l}\text { Bread and } \\
\text { noodle }\end{array}$} & Q2 & 1986 & 538 & 1.05 & $0.93-1.18$ & 1.03 & $0.91-1.17$ \\
\hline & Q3 & 1968 & 525 & 1.03 & $0.91-1.17$ & 0.98 & $0.86-1.11$ \\
\hline & $\widehat{\mathrm{Q}} 4$ & 1954 & 545 & 1.11 & $0.98-1.26$ & 1.05 & $0.92-1.20$ \\
\hline$p$ for trend & & & & 0.1071 & & 0.556 & \\
\hline \multirow{4}{*}{$\begin{array}{c}\text { Whole grain } \\
\text { and soybean } \\
\text { products }\end{array}$} & Q1 & 1985 & 506 & 1.00 & & 1.00 & \\
\hline & Q2 & 1986 & 532 & 0.98 & $0.87-1.11$ & 0.93 & $0.82-1.06$ \\
\hline & $\widehat{\mathrm{Q} 3}$ & 2000 & 545 & 0.94 & $0.83-1.06$ & 0.83 & $0.73-0.94$ \\
\hline & $\mathrm{Q} 4$ & 1929 & 545 & 0.94 & $0.83-1.06$ & 0.82 & $0.72-0.93$ \\
\hline \multicolumn{2}{|l|}{$p$ for trend } & & & 0.2246 & & 0.0006 & \\
\hline \multicolumn{8}{|c|}{ Hypertriglyceridemia } \\
\hline \multirow{4}{*}{$\begin{array}{l}\text { Meat, fish and } \\
\text { vegetables }\end{array}$} & Q1 & 1691 & 532 & 1.00 & & 1.00 & \\
\hline & Q2 & 1672 & 521 & 1.00 & $0.89-1.13$ & 0.99 & $0.87-1.12$ \\
\hline & Q3 & 1695 & 556 & 1.05 & $0.93-1.18$ & 1.03 & $0.90-1.16$ \\
\hline & Q4 & 1678 & 514 & 1.01 & $0.89-1.14$ & 1.00 & $0.87-1.16$ \\
\hline \multirow{2}{*}{$p$ for trend } & & & & 0.806 & & 0.8508 & \\
\hline & Q1 & 1661 & 543 & 1.00 & & 1.00 & \\
\hline \multirow{3}{*}{$\begin{array}{l}\text { Bread and } \\
\text { noodle }\end{array}$} & $\widehat{\mathrm{Q}} 2$ & 1704 & 564 & 0.97 & $0.86-1.09$ & 0.96 & $0.86-1.09$ \\
\hline & Q3 & 1724 & 522 & 0.87 & $0.77-0.99$ & 0.87 & $0.77-0.99$ \\
\hline & $\widetilde{Q} 4$ & 1647 & 494 & 0.86 & $0.76-0.98$ & 0.87 & $0.76-1.00$ \\
\hline$p$ for trend & & & & 0.0126 & & 0.0363 & \\
\hline \multirow{4}{*}{$\begin{array}{l}\text { Whole grain } \\
\text { and soybean } \\
\text { products }\end{array}$} & Q1 & 1653 & 558 & 1.00 & & 1.00 & \\
\hline & Q2 & 1670 & 503 & 0.87 & $0.77-0.98$ & 0.87 & $0.77-0.98$ \\
\hline & Q3 & 1681 & 524 & 0.88 & $0.78-0.99$ & 0.85 & $0.75-0.97$ \\
\hline & $\widehat{\mathrm{Q}} 4$ & 1732 & 538 & 0.87 & $0.77-0.98$ & 0.85 & $0.75-0.97$ \\
\hline$p$ for trend & & & & 0.0613 & & 0.0344 & \\
\hline
\end{tabular}

Model 1 adjusted for age and sex, Model 2 adjusted for age, sex, residual area, education level, household income, current drinking, current smoking, physical activity, total energy intake and BMI, Q: quartile.

\subsection{Interaction of Dietary Pattern with GRS on Dyslipidemia}

Table 4 showed the characteristics of the seven selected SNPs. The minor allele frequency of the seven SNPs ranged from 0.17 to 0.47 and all SNPs were consistent with Hardy-Weinberg equilibrium.

The highest quartile of "whole grain and soybean products" dietary pattern group, compared with lowest dietary pattern group, had significantly lower risk of hypercholesterolemia (HR $=0.74,95 \% \mathrm{CI}$ : $0.59-0.93, p$ for trend $=0.0064$ ) only among participants within the highest GRS tertile and GRS tertile 2 group also showed a tendency to reduce hypercholesterolemia risk ( $p$ for trend $=0.0433$ ) (Table 5 ). But not among those with lower genetic risk. There was marginal interaction $(p$-interaction $=0.0815)$ between dietary patterns and GRS on the risk of hypercholesterolemia. 
Table 4. Characteristics of the seven selected single-nucleotide polymorphisms (SNPs).

\begin{tabular}{|c|c|c|c|c|c|c|c|c|c|c|}
\hline SNP Name & Chromosome & Position & Gene & P-HWE & MAF(ASN) & Ref Allele & Alt Allele & Risk Allele & $p$-Value & Source \\
\hline rs10889353 & 1 & 63118196 & ANGPTL3 & 0.2673 & 0.173 & A & C & C & $3.00 \times 10^{-7}$ & PMID: 19060906 \\
\hline rs7557067 & 2 & 21208211 & $A P O B$ & 0.4536 & 0.272 & A & G & G & $9.00 \times 10^{-12}$ & PMID: 19060906 \\
\hline rs780092 & 2 & 27743154 & GCKR & 0.5279 & 0.326 & A & G & A & $2.00 \times 10^{-9}$ & PMID: 23105936 \\
\hline rs1919127 & 2 & 27801493 & C2orf16 & 0.4481 & 0.474 & $\mathrm{~T}$ & C & $\mathrm{T}$ & $3.00 \times 10^{-11}$ & PMID: 31910446 \\
\hline rs2954029 & 8 & 126490972 & TRIB1 & 0.0774 & 0.442 & $\mathrm{~A}$ & $\mathrm{~T}$ & A & $3.00 \times 10^{-19}$ & PMID: 19060906 \\
\hline rs174547 & 11 & 61570783 & FADS1-FADS2-FADS3 & 0.0739 & 0.322 & $\mathrm{~T}$ & C & $\mathrm{C}$ & $2.00 \times 10^{-14}$ & PMID: 19060906 \\
\hline rs2266788 & 11 & 116660686 & APOA5 & 0.5322 & 0.218 & G & A & A & $2.00 \times 10^{-16}$ & PMID: 31910446 \\
\hline
\end{tabular}

HWE: Hardy-Weinberg equilibrium, MAF: minor allele frequency, ASN: Asian, Ref: reference, Alt: alternate. 
Table 5. Hazard ratios (HR) and 95\% confidence intervals (CI) of dyslipidemia risk according to the joint classifications of the whole grain and soybeans products dietary pattern score and genetic risk scores (GRS) categories.

\begin{tabular}{|c|c|c|c|c|c|c|c|}
\hline \multirow{2}{*}{$\begin{array}{c}\text { GRS } \\
\text { Categories }\end{array}$} & \multirow{2}{*}{$\begin{array}{c}\text { Whole Grain and Soybean } \\
\text { Products Dietary } \\
\text { Pattern Score }\end{array}$} & \multicolumn{3}{|c|}{ Model 1} & \multicolumn{3}{|c|}{ Model 2} \\
\hline & & HR & $95 \% \mathrm{CI}$ & $p$ & HR & $95 \% \mathrm{CI}$ & $p$ \\
\hline \multicolumn{8}{|c|}{ Hypercholesterolemia } \\
\hline & Q1 & 1.00 & & & 1.00 & & \\
\hline GRS & Q2 & 1.20 & $0.92-1.56$ & 0.1857 & 1.12 & $0.86-1.48$ & 0.3999 \\
\hline \multirow[t]{4}{*}{ Tertile 1} & Q3 & 1.22 & $0.94-1.58$ & 0.1365 & 1.08 & $0.83-1.42$ & 0.5537 \\
\hline & Q4 & 1.11 & $0.85-1.44$ & 0.4559 & 1.00 & $0.76-1.32$ & 0.9824 \\
\hline & $p$ for trend & & 0.583 & & & 0.8119 & \\
\hline & Q1 & 1.00 & & & 1.00 & & \\
\hline GRS & Q2 & 1.13 & $0.92-1.40$ & 0.2527 & 1.05 & $0.85-1.30$ & 0.6688 \\
\hline \multirow[t]{4}{*}{ Tertile 2} & Q3 & 1.07 & $0.86-1.32$ & 0.5425 & 0.88 & $0.71-1.09$ & 0.2407 \\
\hline & $\widehat{\mathrm{Q}} 4$ & 1.07 & $0.86-1.33$ & 0.558 & 0.85 & $0.68-1.07$ & 0.1722 \\
\hline & $p$ for trend & & 0.8734 & & & 0.0433 & \\
\hline & Q1 & 1.00 & & & 1.00 & & \\
\hline GRS & Q2 & 0.84 & $0.68-1.04$ & 0.0995 & 0.81 & $0.65-1.01$ & 0.0577 \\
\hline \multirow[t]{4}{*}{ Tertile 3} & Q3 & 0.74 & $0.59-0.92$ & 0.0066 & 0.68 & $0.55-0.86$ & 0.0009 \\
\hline & $\mathrm{Q} 4$ & 0.82 & $0.66-1.02$ & 0.0707 & 0.74 & $0.59-0.93$ & 0.011 \\
\hline & $p$ for trend & & 0.053 & & & 0.0064 & \\
\hline & interaction $=0.0815$ & & & & & & \\
\hline \multicolumn{8}{|c|}{ Hypertriglyceridemia } \\
\hline & Q1 & 1.00 & & & 1.00 & & \\
\hline GRS & Q2 & 0.99 & $0.77-1.28$ & 0.95 & 1.04 & $0.80-1.34$ & 1.232 \\
\hline \multirow[t]{4}{*}{ Tertile 1} & Q3 & 1.06 & $0.83-1.35$ & 0.66 & 1.04 & $0.81-1.33$ & 1.175 \\
\hline & Q4 & 0.92 & $0.71-1.17$ & 0.482 & 0.92 & $0.71-1.20$ & 1.251 \\
\hline & $p$ for trend & & 0.6411 & & & 0.5676 & \\
\hline & Q1 & 1.00 & & & 1.00 & & \\
\hline GRS & Q2 & 0.90 & $0.72-1.11$ & 0.3236 & 0.88 & $0.71-1.10$ & 0.2547 \\
\hline \multirow[t]{4}{*}{ Tertile 2} & Q3 & 0.92 & $0.74-1.13$ & 0.415 & 0.87 & $0.70-1.08$ & 0.1976 \\
\hline & $\mathrm{Q} 4$ & 1.01 & $0.82-1.24$ & 0.9506 & 0.97 & $0.77-1.21$ & 0.7566 \\
\hline & $p$ for trend & & 0.788 & & & 0.8376 & \\
\hline & Q1 & 1.00 & & & 1.00 & & \\
\hline GRS & Q2 & 0.84 & $0.68-1.05$ & 0.1217 & 0.87 & $0.70-1.08$ & 0.2104 \\
\hline \multirow[t]{4}{*}{ Tertile 3} & Q3 & 0.80 & $0.64-1.00$ & 0.0535 & 0.81 & $0.64-1.02$ & 0.0725 \\
\hline & Q4 & 0.83 & $0.67-1.04$ & 0.0992 & 0.87 & $0.69-1.10$ & 0.2556 \\
\hline & $p$ for trend & & 0.1299 & & & 0.2514 & \\
\hline & interaction $=0.5023$ & & & & & & \\
\hline
\end{tabular}

Model 1 adjusted for age and sex, Model 2 adjusted for age, sex, residual area, education level, household income, current drinking, current smoking, physical activity, total energy intake and BMI, Q: quartile.

\section{Discussion}

In this study, three dietary patterns were identified using factor analysis, which are "whole grain and soybean products" pattern, "meat, fish and vegetables" pattern, and "bread and noodle" pattern. During 14-year follow-up period, the "whole grain and soybean products" pattern characterized high intakes of whole grain, soybeans, tofu, and soybean paste was related with a $15 \%$ and $18 \%$ lower risk of hypercholesterolemia and hypertriglyceridemia after adjustment for confounding factors, respectively. Other two dietary patterns were not related to dyslipidemia incidence. The "whole grain and soybean products" pattern is very similar to traditional Korean diet (K-diet) characterized with high consumption of vegetables, moderate to high consumption of legumes and fish, and seasoned with various Jang (fermented soy products), medicinal herbs, and sesame or perilla oil [29]. Dietary pattern analysis is widely used to examine the association between food intake and chronic diseases, because, they not only capture the complex of dietary intake but also explore the relationship with health outcomes [4]. In Western countries, the Mediterranean-style diet or DASH (dietary approaches to 
stop hypertension) are known to associate with dyslipidemia [30,31]. The vegetarian dietary patterns reduce the risk of CHD by about $40 \%$ in a meta-analysis of eight prospective cohort studies [32]. In a Framingham offspring cohort, subjects with a higher Mediterranean-style dietary pattern score (MSDPS) had significantly lower TG $(p<0.001)$ and higher high density lipoprotein (HDL) cholesterol $(p=0.02)$ after adjustment of confounding variables [33]. In the ATTICA study, a dietary pattern involving cereals, fish, legumes, vegetables, and fruits was inversely associated with TGs levels in Greece population [34].

In Korea, several previous studies conducted to examine the relationship between dietary pattern and dyslipidemia. In a cohort analysis, the prudent dietary pattern marked by high intakes of potatoes, legumes, vegetables, mushrooms, fish/shellfish and seaweed, reduced the low incidence of HDL-cholesterolemia to 0.76 in men and 0.78 in women, respectively [18]. In a cross-sectional study, the rice-oriented pattern was significantly increased prevalence of dyslipidemia in Korean adults men $(\mathrm{OR}=1.58, p$ for trend $=0.0042$, for hypertriglyceridemia, $\mathrm{OR}=1.43, p$ for trend $=0.0015$, for low HDL-cholesterol) and women (OR $=1.29, p$ for trend $=0.0020$, for low HDL-cholesterol) using Korea National Health and Nutrition Examination Survey [35]. Another cross-sectional study showed that "oil, sweet, fish and other vegetables" dietary pattern and "grain, bean, nuts, vegetables and fruits" dietary pattern were lower risk of hypertriglyceridemia prevalence $(\mathrm{OR}=0.73, p<0.001$ and $\mathrm{OR}=0.88$, $p=0.009$, respectively) [7]. The Taiwan cross-sectional study showed similar results to our study, the vegetable-fruits-seafood dietary pattern (high intake of vegetables, vegetables with oil or dressing, fruits, seafood, legumes, soy products, and rice or flour products) decreased hypercholesterolemia risk $(\mathrm{OR}=0.89)$ and dairy-complex carbohydrate dietary pattern (high intake of dairy products, milk, root crops, jam or honey, and whole-grain) decreased hypertriglyceridemia $(\mathrm{OR}=0.82)$ in young and middle-aged Taiwanese [8].

A common feature of derived dietary patterns that lowers the risk of dyslipidemia is the high consumption of fiber-rich foods such as fruits, vegetables, and legumes. The whole grain and soybeans contained various nutrients such as dietary fiber, isoflavone, which help lower LDL cholesterol [36]. The soy protein has less hypercholesterolemia effect than casein, replacing dietary cholesterol with soy protein decreases the level of serum cholesterol in humans [37]. The insoluble fibers such as lignin, cellulose, and hemicellulose are rich in whole-grain foods, bran, nuts, and seeds. These fibers can be fermented and used by bacteria as a source of short-chain fatty acids. Therefore, absorption of short-chain fatty acids decreases cholesterol synthesis in the liver and reduces cholesterol levels in the blood [38].

Dyslipidemia is the combination result of the environmental (diet) factors and genetic factors [10]. After the human genome project completed, genome wide association studies have revealed many loci that may influence the lipid metabolism. However, the effect of individual SNPs on complex common disease is relatively weak [39]. Therefore, we examined the interaction between dietary patterns and genetic factors using GRS. The GRS has been used for combine the individual SNPs effects to reveal the complex relationship between CVD and genetic effects [12]. In the Framingham heart study, the 13 SNP GRSs were significantly associated with the incidence of hard CHD (HR $=1.07, p=0.04)$ and CVD (HR for the allele, 1.05, $p=0.03$ ) [14]. Another study used 4 SNP and subjects categorized into 3 GRS group (low 0-1, medium 2-3, and high 4-7), In high GRS group, high daily physical activity reduced the risk of MetS and low carbohydrate diet increased the risk of MetS [40].

In this study, we constructed GRSs composed 7 genetic variants (ANGPTL3 rs10889353, APOB rs7557067, GCKR rs780092, C2orf16 rs1919127, TRIB1 rs2954029, FADS1-FADS2-FADS3 rs174547, and $A P O A 5$ rs2266788) associated with dyslipidemia using GWAS studies [25-27]. To summarize the characteristics of genes [41], ANGPTL3 (Angiopoietin Like 3) is a protein coding gene and associated diseases were familial hypobetalipoproteinemia 1 and 2 which related to the lipoprotein metabolism pathway. $A P O B$ (Apolipoprotein $\mathrm{B}$ ) is a protein coding gene and associated disorder were familial hypobetalipoproteinemia 1 and 2 associated with activated Toll-like receptor (TLR) 4 signaling and lipoprotein metabolism pathway. TRIB1 (Tribbles Pseudokinase 1) is a protein 
coding gene and related ailments were megakaryocytic leukemia and familial hypercholesterolemia. APOA5 (Apolipoprotein A5) is a protein-coding gene and linked disorders were hyperlipoproteinemia Type $\mathrm{V}$ and familial hypertriglyceridemia, lipoprotein metabolism, and lipid signaling pathway. FADS1 (Fatty Acid Desaturase 1) is a protein-coding gene and associated with lipid metabolism disorder and mainly expressed in the liver, and catalyze the desaturation steps in the synthesis of $n-3$ and n-6 polyunsaturated fatty acids. The ANGPTL3 rs10889353, APOB rs7557067, TRIB1 rs2954029, and FADS1-FADS2-FADS3 rs174547 were significantly associated with TG level in meta-analysis of seven GWASs [25] and FADS1-FADS2-FADS3 rs174547 C allele was significantly increased TG level in the Japanese population [42]. Recently, genes associated with high TG level in Koreans were identified as the GCKR rs780092, C2orf16 rs1919127 and APOA5 rs2266788 [27] and the association between rs2266788 in the APOA5 gene and high TG level also reported in Chinese population [43].

We found that the "whole grain and soybean products" dietary pattern related with counted GRS to modulate the risk of the hypercholesterolemia risk in Korean adults. In the high GRS group, the highest quartile of "whole grain and soybean products" dietary pattern score decreased $26 \%$ hypercholesterolemia risk ( $p$ for trend $=0.0064$ ) compared with the lowest quartile. These results suggest that the effect of dietary patterns in reducing the risk of hypercholesterolemia is more effective in the group with higher GRS level. In Framingham Heart Study, high GRS level were positively associated with liver fat accumulation, than those who had low Mediterranean diet score and Alternative Health Eating Index (AHEI) [44]. Furthermore, in a Sweden prospective cohort study, diet quality (based on intakes of saturated fat, polyunsaturated fat, sucrose, fiber, fruit and vegetables, and fish) and HDL-cholesterol change were associated with lower GRS group only [16]. In the PREDIMED-NAVARRA Randomized Trial, Pro/Ala (rs1801282) in the peroxisome proliferator-activated receptor gamma isoform 2 (PPAR $\gamma 2$ ) was associated with telomere length, especially in the group with high adherence to the Mediterranean diet pattern [45]. These results indicate that the effects of dietary factors on disease vary with individual genotypes. Therefore, personalized nutrition therapy is needed considering personal genotype.

This study has several limitations. First, participants of the study lived in a small residual area and included only middle-aged and older adults. Second, the GRS relied upon only seven SNPs discovered from the findings of GWAS analysis which could describe the small portions of dyslipidemia. However, we considered theses minor allele frequency of these SNPs and significances of the analyses and selected the most significant SNP in the same linkage disequilibrium (LD) block.

Also, this study had several strengths. First, we examine the causal relationship between dietary patterns, GRS and dyslipidemia incidence risk using 14-years follow-up prospective cohort study. Second, the three dietary patterns were estimated using a validated SQFFQ collected dietary consumption data for more than 1 year, therefore, this FFQ reflecting long-term dietary intake of participants more than the 24-hr recall.

\section{Conclusions}

In conclusion, for people with genotypes that can cause hypercholesterolemia, eating whole grains and soybean products may have a meaningful response. The results of this study are expected to be utilized for genome-based precision nutrition therapy to treat and prevent dyslipidemia.

Author Contributions: Conceptualization, S.-J.P., M.-S.K. and H.-J.L. methodology, S.-J.P., S.-W.C. and H.-J.L.; formal analysis, S.-J.P.; data curation, S.-J.P.; writing-original draft preparation, S.-J.P. and H.-J.L.; writingreview and editing, H.-J.L., S.-W.C. and M.-S.K. All authors have read and agreed to the published version of the manuscript.

Funding: This research was funded by Korea Food Research Institute (E0150302-06), Republic of Korea.

Acknowledgments: This study was conducted with bioresources from National Biobank of Korea, the Centers for Disease Control and Prevention, Republic of Korea (2016-032).

Conflicts of Interest: The authors declare no conflict of interest. 


\section{References}

1. Kuo, P.T. Dyslipidemia and coronary artery disease. Clin. Cardiol. 1994, 7, 519-527. [CrossRef] [PubMed]

2. Korean Society of Lipidology and Atherosclerosis. Dyslipidemia Fact Sheet in Korea 2015. Available online: https://www.lipid.or.kr/bbs/index.html?code=fact_sheet\&category=\&gubun=\&page=1\&number= 632\&mode $=$ view \&keyfield $=\& k e y=($ accessed on 10 September 2020).

3. Esmaillzadeh, A.; Kimiagar, M.; Mehrabi, Y.; Azadbakht, L.; Hu, F.B.; Willett, W.C. Dietary patterns, insulin resistance, and prevalence of the metabolic syndrome in women. Am. J. Clin. Nutr. 2007, 85, 910-918. [CrossRef]

4. Hu, F.B. Dietary pattern analysis: A new direction in nutritional epidemiology. Curr. Opin. Lipidol. 2002, 13, 3-9. [CrossRef]

5. Kahleova, H.; Levin, S.; Barnard, N.D. Vegetarian Dietary Patterns and Cardiovascular Disease. Prog. Cardiovasc. Dis. 2018, 61, 54-61. [CrossRef] [PubMed]

6. Shan, Z.; Li, Y.; Baden, M.Y.; Bhupathiraju, S.N.; Wang, D.D.; Sun, Q.; Rexrode, K.M.; Rimm, E.B.; Qi, L.; Willett, W.C.; et al. Association Between Healthy Eating Patterns and Risk of Cardiovascular Disease. JAMA Intern. Med. 2020, 180, 1090-1100. [CrossRef] [PubMed]

7. Kim, S.A.; Joung, H.; Shin, S. Dietary pattern, dietary total antioxidant capacity, and dyslipidemia in Korean adults. Nutr. J. 2019, 18, 37. [CrossRef]

8. Lin, L.Y.; Hsu, C.Y.; Lee, H.A.; Wang, W.H.; Kurniawan, A.L.; Chao, J.C. Dietary Patterns in Relation to Components of Dyslipidemia and Fasting Plasma Glucose in Adults with Dyslipidemia and Elevated Fasting Plasma Glucose in Taiwan. Nutrients 2019, 11, 845. [CrossRef] [PubMed]

9. Na, W.; Chung, B.; Shon, C. A Relationship between Dietary Patterns and Dyslipidemia in Urban-dwelling Middle-Aged Korean Men: Using Korean Genome and Epidemiology Study (KoGES). Clin. Nutr. Res. 2019, 8, 219-228. [CrossRef]

10. Hannon, B.A.; Khan, N.A.; Teran-Garcia, M. Nutrigenetic Contributions to Dyslipidemia: A Focus on Physiologically Relevant Pathways of Lipid and Lipoprotein Metabolism. Nutrients 2018, 10, 1404. [CrossRef]

11. Ordovas, J.M.; Corella, D.; Kaput, J. Nutrient-gene interactions in lipoprotein metabolism-An overview. Forum Nutr. 2007, 60, 102-109. [CrossRef]

12. Morrison, A.C.; Bare, L.A.; Chambless, L.E.; Ellis, S.G.; Malloy, M.; Kane, J.P.; Pankow, J.S.; Devlin, J.J.; Willerson, J.T.; Boerwinkle, E. Prediction of coronary heart disease risk using a genetic risk score: The Atherosclerosis Risk in Communities Study. Am. J. Epidemiol. 2007, 166, 28-35. [CrossRef] [PubMed]

13. Cooke Bailey, J.N.; Igo, R.P., Jr. Genetic Risk Scores. Curr. Protoc. Hum. Genet. 2016, 91, 1-29. [CrossRef] [PubMed]

14. Thanassoulis, G.; Peloso, G.M.; Pencina, M.J.; Hoffmann, U.; Fox, C.S.; Cupples, L.A.; Levy, D.; D'Agostino, R.B.; Hwang, S.J.; O'Donnell, C.J. A genetic risk score is associated with incident cardiovascular disease and coronary artery calcium: The Framingham Heart Study. Circ. Cardiovasc. Genet. 2012, 5, 113-121. [CrossRef] [PubMed]

15. Fujii, T.M.M.; Norde, M.M.; Fisberg, R.M.; Marchioni, D.M.L.; Rogero, M.M. Lipid metabolism genetic risk score interacts with the Brazilian Healthy Eating Index Revised and its components to influence the odds for dyslipidemia in a cross-sectional population-based survey in Brazil. Nutr. Health 2019, 25, 119-126. [CrossRef] [PubMed]

16. Sonestedt, E.; Hellstrand, S.; Drake, I.; Schulz, C.A.; Ericson, U.; Hlebowicz, J.; Persson, M.M.; Gullberg, B.; Hedblad, B.; Engström, G.; et al. Diet Quality and Change in Blood Lipids during 16 Years of Follow-up and Their Interaction with Genetic Risk for Dyslipidemia. Nutrients 2016, 8, 274. [CrossRef] [PubMed]

17. Song, S.; Paik, H.Y.; Park, M.; Song, Y. Dyslipidemia patterns are differentially associated with dietary factors. Clin. Nutr. 2016, 35, 885-891. [CrossRef] [PubMed]

18. Lee, J.; Kim, J. Association between Dietary Pattern and Incidence of Cholesterolemia in Korean Adults: The Korean Genome and Epidemiology Study. Nutrients 2018, 10, 53. [CrossRef]

19. Kim, Y.; Han, B.G. Cohort Profile: The Korean Genome and Epidemiology Study (KoGES) Consortium. Int. J. Epidemiol. 2017, 46, 1350. [CrossRef]

20. Ahn, Y.; Kwon, E.; Shim, J.E.; Park, M.K.; Joo, Y.; Kimm, K.; Park, C.; Kim, D.H. Validation and reproducibility of food frequency questionnaire for Korean genome epidemiologic study. Eur. J. Clin. Nutr. 2007, 61, 1435-1441. [CrossRef] 
21. The Korean Nutrition Society. Food Composition Table in Recommended Dietary Allowances for Koreans 7 th Revision; The Korean Nutrition Society: Seoul, Korea, 2000.

22. Rhee, E.J.; Kim, H.C.; Kim, J.H.; Lee, E.Y.; Kim, B.J.; Kim, E.M.; Song, Y.; Lim, J.H.; Kim, H.J.; Choi, S.; et al. 2018 Guidelines for the management of dyslipidemia. Korean J. Intern. Med. 2019, 34, 723-771. [CrossRef]

23. Miller, M.; Stone, N.J.; Ballantyne, C.; Bittner, V.; Criqui, M.H.; Ginsberg, H.N.; Goldberg, A.C.; Howard, W.J.; Jacobson, M.S.; Kris-Etherton, P.M.; et al. Triglycerides and cardiovascular disease: A scientific statement from the American Heart Association. Circulation 2011, 123, 2292-2333. [CrossRef]

24. Kim, Y.; Kim, J.; Lim, J.E.; Oh, B.; Won, S.; Kim, M. Genome-wide interaction study of single-nucleotide polymorphisms and alcohol consumption on blood pressure: The Ansan and Ansung study of the Korean Genome and Epidemiology Study (KoGES). Genet. Epidemiol. 2020, 44, 300-310. [CrossRef] [PubMed]

25. Kathiresan, S.; Willer, C.J.; Peloso, G.M.; Demissie, S.; Musunuru, K.; Schadt, E.E.; Kaplan, L.; Bennett, D.; Li, Y.; Tanaka, T.; et al. Common variants at 30 loci contribute to polygenic dyslipidemia. Nat. Genet. 2009, 41, 56-65. [CrossRef] [PubMed]

26. Go, M.J.; Hwang, J.Y.; Kim, D.J.; Lee, H.J.; Jang, H.B.; Park, K.H.; Song, J.; Lee, J.Y. Effect of genetic predisposition on blood lipid traits using cumulative risk assessment in the Korean population. Genom. Inform. 2012, 10, 99-105. [CrossRef] [PubMed]

27. Oh, S.; Lee, J.E.; Shin, E.; Kwon, H.; Choe, E.K.; Choi, S.; Rhee, H.; Choi, S.H. Genome-wide association study of metabolic syndrome in Korean populations. PLoS ONE 2020, 15, e227357. [CrossRef]

28. Villegas, R.; Delahanty, R.; Gao, Y.T.; Long, J.; Williams, S.M.; Xiang, Y.B.; Cai, H.; Li, H.L.; Hu, F.; Cai, Q.; et al. Joint effect of genetic and lifestyle risk factors on type 2 diabetes risk among Chinese men and women. PLOS ONE 2012, 7, e49464. [CrossRef]

29. Kim, S.H.; Kim, M.S.; Lee, M.S.; Park, Y.S.; Lee, H.J.; Kang, S.; Lee, H.S.; Lee, K.E.; Yang, H.J.; Kim, M.J.; et al. Korean diet: Characteristics and historical background. J. Ethn. Foods 2016, 3, 26-31. [CrossRef]

30. Siervo, M.; Lara, J.; Chowdhury, S.; Ashor, A.; Oggioni, C.; Mathers, J.C. Effects of the Dietary Approach to Stop Hypertension (DASH) diet on cardiovascular risk factors: A systematic review and meta-analysis. Br. J. Nutr. 2015, 113, 1-15. [CrossRef]

31. Tosti, V.; Bertozzi, B.; Fontana, L. Health Benefits of the Mediterranean Diet: Metabolic and Molecular Mechanisms. J. Gerontol. Ser. A Biol. Sci. Med. Sci. 2018, 73, 318-326. [CrossRef]

32. Dinu, M.; Abbate, R.; Gensini, G.F.; Casini, A.; Sofi, F. Vegetarian, vegan diets and multiple health outcomes: A systematic review with meta-analysis of observational studies. Crit. Rev. Food Sci. Nutr. 2017, 57, 3640-3649. [CrossRef]

33. Rumawas, M.E.; Meigs, J.B.; Dwyer, J.T.; McKeown, N.M.; Jacques, P.F. Mediterranean-style dietary pattern, reduced risk of metabolic syndrome traits, and incidence in the Framingham Offspring Cohort. Am. J. Clin. Nutr. 2009, 90, 1608-1614. [CrossRef]

34. Panagiotakos, D.B.; Pitsavos, C.; Skoumas, Y.; Stefanadis, C. The association between food patterns and the metabolic syndrome using principal components analysis: The ATTICA Study. J. Am. Diet. Assoc. 2007, 107, 979-987. [CrossRef]

35. Song, S.J.; Lee, J.E.; Paik, H.Y.; Park, M.S.; Song, Y.J. Dietary patterns based on carbohydrate nutrition are associated with the risk for diabetes and dyslipidemia. Nutr. Res. Pract. 2012, 6, 349-356. [CrossRef]

36. National Cholesterol Education Program (NCEP) Expert Panel on Detection, Evaluation, and Treatment of High Blood Cholesterol in Adults (Adult Treatment Panel III). Third Report of the National Cholesterol Education Program (NCEP) Expert Panel on Detection, Evaluation, and Treatment of High Blood Cholesterol in Adults (Adult Treatment Panel III) final report. Circulation 2002, 106, 3143-3421. [CrossRef]

37. Carroll, K.K.; Kurowska, E.M. Soy consumption and cholesterol reduction: Review of animal and human studies. J. Nutr. 1995, 125, 594s-597s. [CrossRef]

38. Soliman, G.A. Dietary Fiber, Atherosclerosis, and Cardiovascular Disease. Nutrients 2019, 11, 1155. [CrossRef]

39. Läll, K.; Mägi, R.; Morris, A.; Metspalu, A. Personalized risk prediction for type 2 diabetes: The potential of genetic risk scores. Genet. Med. 2017, 19, 322-329. [CrossRef]

40. Zhou, J.Y.; Song, M.Y.; Park, S. Carbohydrate and sodium intake and physical activity interact with genetic risk scores of four genetic variants mainly related to lipid metabolism to modulate metabolic syndrome risk in Korean middle-aged adults. Br. J. Nutr. 2019, 122, 919-927. [CrossRef]

41. The Human Gene Database. Available online: http://www.genecards.org/ (accessed on 1 November 2020). 
42. Nakayama, K.; Bayasgalan, T.; Tazoe, F.; Yanagisawa, Y.; Gotoh, T.; Yamanaka, K.; Ogawa, A.; Munkhtulga, L.; Chimedregze, U.; Kagawa, Y.; et al. A single nucleotide polymorphism in the FADS1/FADS2 gene is associated with plasma lipid profiles in two genetically similar Asian ethnic groups with distinctive differences in lifestyle. Hum. Genet. 2010, 127, 685-690. [CrossRef]

43. Shou, W.; Wang, Y.; Xie, F.; Wang, B.; Yang, L.; Wu, H.; Wang, Y.; Wang, Z.; Shi, J.; Huang, W. A functional polymorphism affecting the APOA5 gene expression is causally associated with plasma triglyceride levels conferring coronary atherosclerosis risk in Han Chinese Population. Biochim. Biophys. Acta 2014, 1842, 2147-2154. [CrossRef]

44. Ma, J.; Hennein, R.; Liu, C.; Long, M.T.; Hoffmann, U.; Jacques, P.F.; Lichtenstein, A.H.; Hu, F.B.; Levy, D. Improved Diet Quality Associates With Reduction in Liver Fat, Particularly in Individuals With High Genetic Risk Scores for Nonalcoholic Fatty Liver Disease. Gastroenterology 2018, 155, 107-117. [CrossRef]

45. García-Calzón, S.; Martínez-González, M.A.; Razquin, C.; Corella, D.; Salas-Salvadó, J.; Martínez, J.A.; Zalba, G.; Marti, A. Pro12Ala polymorphism of the PPAR $\gamma 2$ gene interacts with a mediterranean diet to prevent telomere shortening in the PREDIMED-NAVARRA randomized trial. Circ. Cardiovasc. Genet. 2015, 8, 91-99. [CrossRef]

Publisher's Note: MDPI stays neutral with regard to jurisdictional claims in published maps and institutional affiliations.

(C) 2020 by the authors. Licensee MDPI, Basel, Switzerland. This article is an open access article distributed under the terms and conditions of the Creative Commons Attribution (CC BY) license (http://creativecommons.org/licenses/by/4.0/). 